\title{
ADEQUAÇÃO DO TESTE DE TETRAZÓLIO PARA SEMENTES DE ALGODOEIRO ${ }^{1}$
}

\author{
FERNANDA CERVI², ELISABETH APARECIDA FURTADO MENDONÇA ${ }^{3}$
}

\begin{abstract}
RESUMO - O teste de tetrazólio destaca-se entre os demais testes devido à possibilidade de avaliar simultaneamente a viabilidade e o vigor de sementes. A recomendação existente para condução deste teste com sementes de algodoeiro é morosa, além de apresentar dificuldades na forma de preparo e avaliação. Diante do fato, este trabalho teve por objetivo a redução do tempo de preparo das sementes de algodoeiro para a execução do teste. Inicialmente foram realizados três ensaios: 1- corte distal seguido de corte longitudinal: após o pré-umedecimento em papel e imersão em água por seis, oito e 16 horas, respectivamente; 2- corte distal nas sementes secas: seguido de imersão direta em água por quatro, seis e oito horas e, em papel, por 16 horas; 3- imersão - corte - imersão: após duas horas de imersão, foi feito o corte na extremidade oposta ao eixo embrionário seguido de imersão em água por quatro, seis e oito horas a $25^{\circ} \mathrm{C}$. O tratamento corte distal do lado oposto do embrião após duas horas de imersão, seguida de mais seis horas de embebição, reduziu o tempo e facilitou o preparo das sementes para condução do teste. Em seguida, foram testadas as concentrações de tetrazólio $0,1 \%$ e $0,075 \%$ e as temperaturas 30,35 e $40^{\circ} \mathrm{C}$. Posteriormente, foi realizada a validação da metodologia proposta, com cinco lotes de sementes, em que foram comparados os resultados com os da germinação e primeira contagem. Conclui-se que, para as sementes de algodoeiro, o teste de tetrazólio deve ser executado da seguinte forma: imersão em água por duas horas, seguido de corte na extremidade oposta ao eixo embrionário e posterior imersão por mais seis horas em água, seguida da remoção do tegumento e da membrana interna e, por fim, as sementes devem ser colocadas em solução de tetrazólio a $0,075 \%$ e mantidas em estufa a $40^{\circ} \mathrm{C}$ por 150 minutos.
\end{abstract}

Termos para indexação: Gossypium hirsutum, ajuste de metodologia, pré-condicionamento.

\section{TETRAZOLIUM TEST ADJUSTMENT FOR COTTON SEEDS}

\begin{abstract}
The tetrazolium test stands out among other tests because it allows the simultaneous evaluation of seed viability and vigor. The existing recommendation for conducting the test with cotton seeds is rather slow and presents difficulties in the way of preparing and evaluating seeds. Considering this fact, this study aimed to reduce cotton seed preparation time in order to conduct the test. Three assays were conducted initially: 1- distal cut followed by a longitudinal cut, after premoistening the seeds in paper and immersing them in water for six, eight, and 16 hours, respectively; 2- distal cut on dry seeds, followed by direct immersion in water for four, six, and eight hours, and in paper for 16 hours; 3- immersion - cut - immersion: after immersion for two hours, the end opposite to the embryo axis was cut, and immersion in water followed for four, six, and eight hours
\end{abstract}

${ }^{1}$ Submetido em 23/06/2008. Aceito para publicação em 26/01/2009. Parte da Dissertação de Mestrado do primeiro autor apresentada ao PPAT/ FAMEV/UFMT.

${ }^{2}$ Bióloga, aluna do Mestrado em Agricultura Tropical, Faculdade de
Agronomia e Medicina Veterinária/FAMEV/UFMT, Av. Fernando Correa s/nº 78060-900,Cuiabá-MT. nanda_ufmt@yahoo.com.br

${ }^{3}$ Dr, Docente do Programa de Pós-graduação em Agricultura Tropical, FAMEV, UFMT, Cuiabá-MT. beth@ufmt.br 
at $25^{\circ} \mathrm{C}$. The treatment involving a distal cut on the side opposite to the embryo after immersion for two hours, followed by imbibition for a further six hours reduced the time required and facilitated seed preparation for the test. Next, tetrazolium concentrations of $0.1 \%$ and $0.075 \%$ were tested at temperatures of 30,35 and $40^{\circ} \mathrm{C}$. Later, the proposed methodology was validated using five seed lots, by comparing the results obtained with germination and first count results. From the results obtained, it was concluded that, for cotton seeds, the tetrazolium test should be conducted in the following manner: immersion of seeds in water for two hours, followed by a cut on the end opposite to the embryo axis, and then immersion for another six hours in water, followed by removal of the integument plus the inner membrane and, finally, the seeds should be placed in tetrazolium solution at $0.075 \%$ and maintained in an incubator at $40^{\circ} \mathrm{C}$ for 150 minutes

Index terms: Gossypium hirsutum, methodology adjustment, pre-conditioning

\section{INTRODUÇÃO}

$\mathrm{O}$ desenvolvimento de testes rápidos visando à determinação da qualidade fisiológica de sementes tem sido um dos principais objetivos dos tecnologistas de semente há vários anos, principalmente por permitir a tomada de decisão rápida nos programas de controle de qualidade. Dentre esses testes, destaca-se o teste de tetrazólio por possibilitar a avaliação do potencial fisiológico das sementes com rapidez e eficiência quando executado criteriosamente.

O teste de tetrazólio é utilizado comumente para analisar sementes de grandes culturas, tais como: soja (França Neto, 1998), milho (Dias e Barros, 1999), feijão (Bhering et al., 1996) algodão (Vieira e Von Pinho, 1999), amendoim (Bittencourt e Vieira, 1999), café (Araújo et al., 1997) e braquiária (Dias e Alves, 2001).

$\mathrm{O}$ teste apresenta vantagens pelo fato de não sofrer interferência de diversas condições que podem alterar os resultados como ocorre no teste padrão de germinação, como a presença de fungos; avaliar as condições físicas e fisiológicas do embrião de cada semente individualmente; permitir rápida avaliação da viabilidade; possibilitar, em algumas espécies, como soja, algodão e feijão, por meio da observação da coloração obtida nas diferentes partes da semente, a localização e a natureza das alterações nos tecidos das sementes e, classificar as alterações de vigor . Pode, ainda, fornecer o diagnóstico da causa da perda da viabilidade das sementes, além de requerer equipamento simples e barato para sua execução (Delouche et al., 1976; França Neto et al., 1998; França Neto, 1999).

O teste fundamenta-se na alteração da coloração dos tecidos da semente em presença de solução de sal de tetrazólio, devido à atividade das enzimas desidrogenases, durante a respiração, onde ocorre a liberação de íons hidrogênios com os quais o sal 2,3,5 trifenil cloreto de tetrazólio, incolor e solúvel, reage com os tecidos vivos formando uma substância de cor vermelha e insolúvel denominada formazan (Delouche et al., 1976). Tecidos mortos ou muito deteriorados apresentam-se descoloridos. O padrão de coloração dos tecidos pode ser utilizado para identificar sementes viáveis, não viáveis e, dentro da categoria viável, as de alto e baixo vigor (Vieira e Von Pinho, 1999).

A eficiência do teste em avaliar o vigor e a viabilidade das sementes está relacionada ao desenvolvimento de uma metodologia adequada para cada espécie, de modo a definir as condições mais apropriadas para o pré-condicionamento, preparo e coloração das sementes, pois, essas etapas antes da coloração são decisivas na obtenção de resultados precisos.

A recomendação da metodologia do teste de tetrazólio para sementes de algodoeiro estabelece um período de 14-16 horas a $25^{\circ} \mathrm{C}$ de pré-condicionamento das sementes para a realização do teste (Vieira e Von Pinho, 1999), entretanto, a mesma não se refere à forma como é feita a remoção do tegumento e da membrana interna. Segundo as Regras de Análises deSementes(Brasil, 1992), para o gênero Gossypium, recomenda-se o corte longitudinal através da metade distal ou remoção do tegumento a partir da extremidade distal como pré-condicionamento após a embebição em papel umedecido por 18 horas, para coloração a concentração da solução 1,0\% a $30^{\circ} \mathrm{C}$ por seis a 24 horas. Na prática, a execução do teste da forma em que é recomendada, tem limitações, pois como as sementes de algodoeiro apresentam tegumento espesso e uma membrana interna, a remoção é difícil e provoca, muitas vezes, ferimentos nos cotilédones dificultando e mascarando 
os resultados.

Tendo em vista as dificuldades de execução do teste, este estudo teve o propósito de determinar a melhor maneira de expor os tecidos do embrião ao sal de tetrazólio, sem danificálos, para facilitar e reduzir o tempo de preparo das sementes bem como verificar se a redução da concentração do sal de tetrazólio permite executar as avaliações da coloração sem aumento do tempo de execução do teste.

\section{MATERIAL E MÉTODOS}

Os ensaios foram realizados no Laboratório de Análise de Sementes da Faculdade de Agronomia e Medicina Veterinária da Universidade Federal de Mato Grosso, no período de setembro de 2006 a julho de 2007.

Para o estudo do teste de tetrazólio foram utilizadas sementes de algodoeiro da cultivar FMT 701, safras 2005/2006 e 2006/2007. Neste estudo, foram testadas técnicas alternativas de pré-condicionamento, preparo, concentrações de solução de tetrazólio, temperatura, redução do tempo de execução do teste e, finalmente a aplicabilidade das alterações propostas para adequação do teste para sementes de algodoeiro.

Como testes preliminares as recomendações contidas nas Regras para Análise de Sementes - RAS (Brasil, 1992) para realização do teste de tetrazólio para as sementes do gênero Gossypium foram adotadas. Para tanto, foi realizado o preparo das sementes na seguinte seqüência: punção no tegumento antes do pré-condicionamento e embebição em água por 18 horas; como preparo antes da coloração, foi feito o corte longitudinal através da metade distal e, após a coloração, a bissecção longitudinal para remoção do tegumento.

Visando facilitar e reduzir o tempo de preparo das sementes de algodoeiro três ensaios foram realizados: 1) corte distal seguido de corte longitudinal (Figura 1) - realizados do lado oposto ao embrião fazendo-se um pequeno corte com estilete com remoção do fragmento na extremidade oposta ao embrião e, outro corte na parte lateral, sem atingir o embrião, a partir da extremidade distal até a metade da semente, após o pré-umedecimento em papel toalha com 2,5 vezes sua massa seca e imersão em água por seis, oito e 16 horas, em câmara de germinação a $25^{\circ} \mathrm{C}$, respectivamente. Após cada tratamento, o tegumento das sementes foi removido manualmente, 2) corte distal nas sementes antes do précondicionamento (Figura 2) - foi feito um corte distal nas sementes secas na região oposta ao embrião, com remoção do fragmento. Após o corte, as sementes foram colocadas para embeber em água - imersão direta - por quatro, seis e oito horas, e em papel toalha por 16 horas, em câmara de germinação a $25^{\circ} \mathrm{C}$. Para remoção do tegumento, após as duas formas de pré-umedecimento, foi necessário retirar pequena parte do tegumento a partir da extremidade cortada e, em seguida pressionar levemente a semente para extraí-la do tegumento. Após a remoção do tegumento, as sementes oriundas dos períodos de embebição por seis e oito horas foram colocadas imersas em água, em temperatura ambiente, para o término da remoção da membrana interna que envolve os cotilédones. 3) imersão - corte - imersão (Figura 3) as sementes foram mantidas em imersão direta em água por $30 \mathrm{~min}, 1 \mathrm{~h}$ e $2 \mathrm{~h}$ para verificar qual o período de embebição facilitaria o corte distal. As imersões por $30 \mathrm{~min}$ e $1 \mathrm{~h}$ não foram suficientes para facilitar o corte. Foi selecionado o período de duas horas de imersão em água antes do corte na extremidade oposta ao eixo embrionário e, em seguida, as sementes foram colocadas novamente em imersão direta em água por quatro, seis e oito horas, em câmara de germinação a $25^{\circ} \mathrm{C}$, para posterior retirada do tegumento.
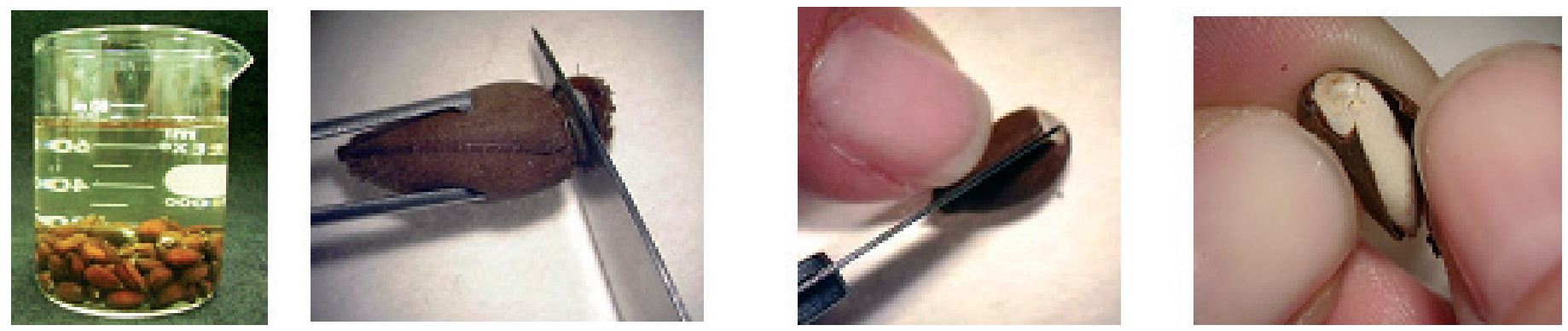

FIGURA 1. Ensaio 1: Imersão em água por $2 \mathrm{~h}$, seguida de corte na extremidade distal e posterior corte longitudinal para remoção do tegumento. 

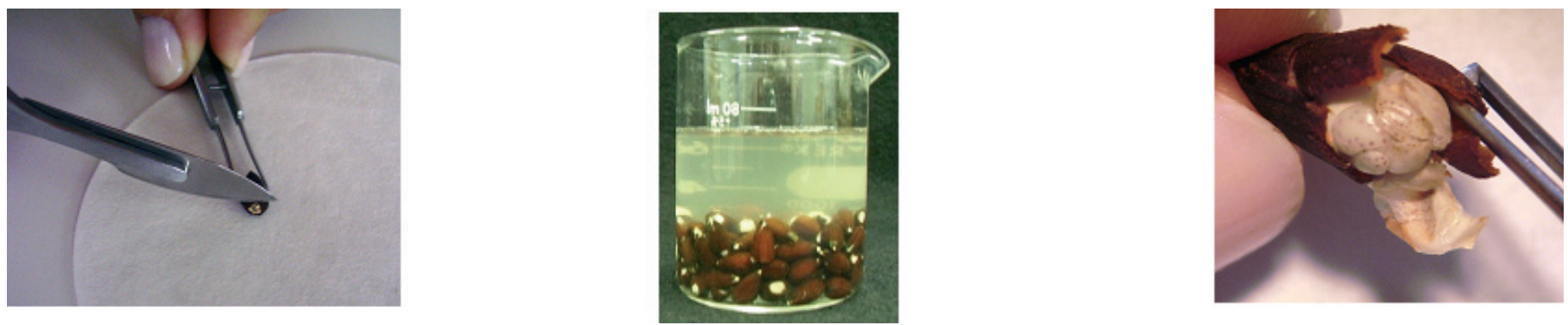

FIGURA 2. Ensaio 2: Corte distal antes do pré-condicionamento, seguido de imersão em água por $6 \mathrm{~h}$, 8h e $16 \mathrm{~h}$ e remoção a partir da extremidade distal.
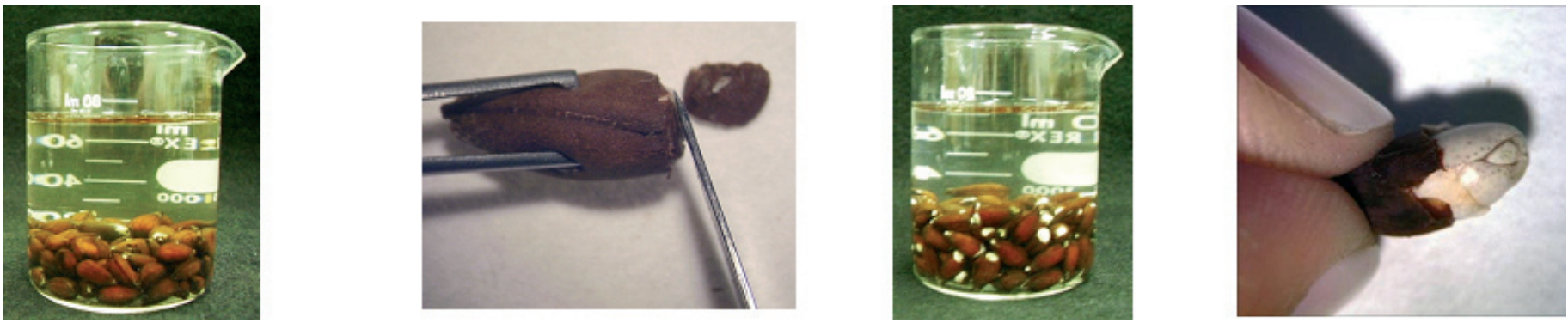

FIGURA 3. Ensaio 3: Imersão em água por $2 \mathrm{~h}$, seguida de corte na extremidade distal, com mais 6 h de imersão em água e posterior remoção do tegumento

Para os três ensaios, foi computado o tempo gasto para realização do preparo da amostra (100 sementes) antes da coloração, para verificar a redução do tempo médio de preparo e também, foi feita uma avaliação criteriosa para verificar se as formas de preparo estudadas provocaram danos ao embrião.

Após o pré-condicionamento e posterior remoção completa do tegumento e da membrana interna, os embriões foram imersos em solução de tetrazólio a $0,1 \%$, concentração recomendada para sementes de algodoeiro (Vieira e Von Pinho, 1999) sob a temperatura de $40^{\circ} \mathrm{C}$ para incubação, por permitir ganho de tempo para atingir coloração adequada. Nessas condições, os embriões foram mantidos no escuro em estufa incubadora por duas horas. Decorrido esse período, foram lavados em água corrente e em seguida analisados em estereomicroscópio acoplado a um monitor de 15 polegadas, onde foi avaliada primeiramente a parte externa, e, em seguida, foi feito o corte longitudinal a partir do centro do embrião, para avaliação das estruturas internas.

Para cada ensaio, a fim de verificar se a técnica em estudo possibilitou facilitar e reduzir o tempo de preparo e pré-condicionamento, cada semente foi avaliada seguindo os seguintes critérios: tegumento externo e membrana interna removidos concomitantemente; porcentagem de danos provocados na remoção, uniformidade da coloração, sem manchas vermelho-intensas; dificuldade para realizar o corte, tegumento ainda duro; tempo de preparo (corte e remoção do tegumento - em minutos); facilidade para retirar o tegumento; porcentagem de danos provocados, distinguíveis dos danos fisiológicos da semente; porcentagem de injúrias causadas no corte (tecido branco) e porcentagem de sementes sem danos provocados durante o preparo.

Definida a melhor técnica de pré-condicionamento e preparo das sementes, foram realizados os estudos da concentração do sal de tetrazólio e o tempo de coloração das sementes oriundas de duas safras, 2005/2006 e 2006/2007, com o intuito de verificar se a redução da concentração permitiria a obtenção da coloração adequada, sem alterar na análise dos resultados, bem como observar se a diferença da idade das sementes poderia interferir no tempo de coloração.

Para a remoção do tegumento, as sementes foram cortadas na extremidade oposta ao eixo embrionário após duas horas de imersão em água, seguida de mais seis horas 
de imersão depois do corte. Na seqüência, as sementes foram totalmente imersas na solução de tetrazólio, em copos de plásticos de $50 \mathrm{~mL}$, acondicionados em estufa a 30,35 e $40^{\circ} \mathrm{C}$ e mantidos no escuro. Os tratamentos consistiram em duas concentrações de tetrazólio $(0,1 \%$ e $0,075 \%)$ com cinco repetições de 20 sementes.

A cada 30 minutos foi avaliado o desenvolvimento da coloração para determinar o período mais adequado para cada concentração da solução de tetrazólio. Durante cinco horas, em intervalos de 30 minutos, as amostras foram retiradas e avaliadas, prosseguindo-se dessa forma até que as sementes atingissem excesso de cor na menor concentração.

Durante o período de incubação, para cada tratamento, foi analisado o padrão de coloração (Figura 4) apresentado pelas sementes: a) ausência de coloração (sem cor), b) leve coloração da semente com tom de rosa mais forte na extremidade da radícula (inicial), c) boa tonalidade de rosa (adequado) e d) vermelho intenso (excessivo) (Mendonça et al., 2001 e 2006).
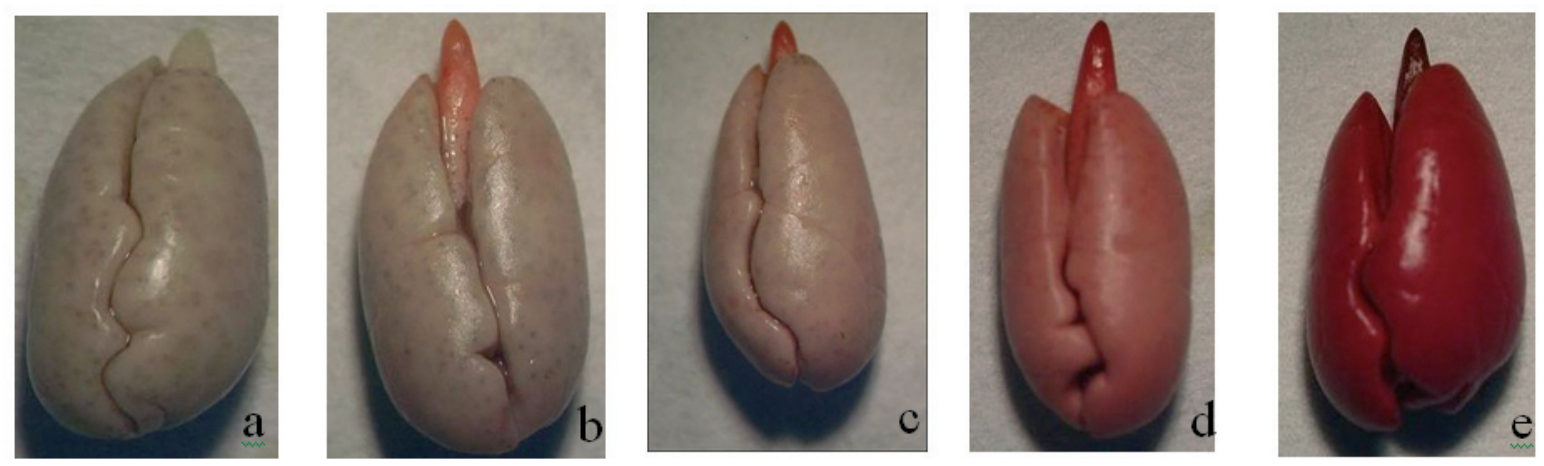

FIGURA 4. Sementes de algodoeiro submetidas ao teste de tetrazólio avaliadas quanto à coloração: a) sem cor, b) início de coloração, c) fraco d) adequado e e) excesso.

Para a validação da metodologia proposta, foram utilizados cinco lotes de sementes de algodoeiro a fim de verificar a aplicabilidade da metodologia do teste de tetrazólio estudada. Quatro subamostras de 25 sementes de cinco lotes de algodoeiro, distintos dos demais lotes utilizados em outras etapas do trabalho, foram submetidas às técnicas de pré-condicionamento e preparo que proporcionaram maior facilidade de remoção do tegumento e consequente redução do tempo de exposição das sementes ao sal de tetrazólio, na concentração de $0,075 \%$ a $40^{\circ} \mathrm{C}$.

Depois de coloridas, as sementes foram lavadas em água corrente e analisadas em estereomicroscópio acoplado a um monitor de 15 polegadas, onde foi avaliada primeiramente a parte externa da semente e, em seguida, foi feito o corte longitudinal a partir do centro do embrião, para avaliação das estruturas internas. $\mathrm{Na}$ avaliação as sementes foram classificadas de acordo com os critérios de Vieira e Von Pinho (1999) em oito classes: 1 a 3: vigorosas, 1 a 5: viáveis e 6 a 8: inviáveis.

Os resultados desse teste foram comparados com o teste de germinação e a primeira contagem, conduzidos com quatro subamostras de 25 sementes em papel toalha, na forma de rolo, a $25^{\circ} \mathrm{C}$ em câmara de germinação (Brasil, 1992).

\section{Procedimento estatístico}

Para validação da metodologia do tetrazólio, foi aplicado o delineamento inteiramente casualizado no teste de germinação, nos resultados da primeira contagem e teste de tetrazólio. Os dados foram submetidos à análise de variância pelo teste $\mathrm{F}$ e as médias comparadas pelo teste de Tukey a $5 \%$ de probabilidade.

\section{RESULTADOS E DISCUSSÃO}

\section{Pré-condicionamento}

Apartirdas avaliações preliminares foramestabelecidosos critérios e os procedimentos que seriam utilizados na tentativa de reduzir e facilitar o pré-condicionamento e preparo, para aplicação do teste de tetrazólio para sementes de algodoeiro. Quando se seguiu as recomendações estabelecidas nas RAS (Brasil, 1992) para o gênero Gossypium, observou-se que a execução do teste foi morosa, além de ser difícil a remoção do tegumento, provocando inúmeros ferimentos e danos nos cotilédones das sementes, mascarando os resultados. Vieira e Von Pinho (1999) relataram que a remoção do tegumento, após o pré-condicionamento, geralmente possibilita maior 
uniformidade e rapidez no desenvolvimento da coloração, entretanto, os resultados podem ser alterados em virtude da ocorrência de danos ao embrião, durante essa fase.

Em decorrência das dificuldades encontradas, foi necessário buscar novas maneiras de expor os tecidos da semente ao sal de tetrazólio, cujos resultados encontramse na Tabela 1. Procedeu-se inicialmente, o ensaio de corte distal na extremidade oposta ao embrião, seguido do corte longitudinal na lateral da semente, após vários períodos de pré-condicionamento, primeiramente com as sementes préembebidas em papel. Esse procedimento demandou em torno de uma hora para execução, e as técnicas empregadas para o preparo não foram suficientes para a remoção concomitante do tegumento externo e da membrana interna. Foi necessário colocar novamente as sementes em imersão para a retirada da membrana interna, e mesmo assim, esse procedimento causou ferimentos provocados por "unhas", o que dificultou a interpretação dos resultados.

TABELA 1. Resultados dos três ensaios utilizados para reduzir o tempo e a forma de preparo das sementes de algodoeiro para adequação do teste de tetrazólio.

\begin{tabular}{|c|c|c|c|c|c|c|c|c|c|c|c|c|c|c|}
\hline \multirow{5}{*}{ Descritores } & \multicolumn{14}{|c|}{ Ensaios - Forma de preparo das sementes para execução do teste de tetrazólio } \\
\hline & \multicolumn{5}{|c|}{ 1.Corte distal + longitudinal } & \multicolumn{6}{|c|}{ 2.Corte distal nas sementes secas } & \multicolumn{3}{|c|}{ 3.Imersão-corte-imersão } \\
\hline & \multicolumn{3}{|c|}{ Papel } & \multicolumn{2}{|c|}{ Imersão } & \multicolumn{2}{|c|}{ Papel } & \multicolumn{4}{|c|}{ Imersão } & & & \\
\hline & \multicolumn{14}{|c|}{ Tempo de pré-condicionamento (h) } \\
\hline & 6 & 8 & 16 & 6 & 8 & 16 & 16 & 4 & 6 & 8 & 16 & $2+4$ & $2+6$ & $2+8$ \\
\hline $\begin{array}{l}\text { Ensaios onde o tegumento } \\
\text { externo e membrana } \\
\text { interna da semente foram } \\
\text { removidos } \\
\text { concomitantemente após o } \\
\text { preparo }\end{array}$ & & & & & & $\mathrm{X}$ & $\mathrm{X}$ & $\mathrm{X}$ & $\mathrm{X}$ & $\mathrm{X}$ & $\mathrm{X}$ & & $X$ & $X$ \\
\hline $\begin{array}{l}\text { Porcentagem de danos } \\
\text { provocados na remoção }\end{array}$ & 61 & 56 & 44 & 53 & 51 & 20 & 48 & 75 & 54 & 14 & 17 & 32 & 10 & 42 \\
\hline $\begin{array}{l}\text { Presença de coloração } \\
\text { uniforme, sem manchas } \\
\text { vermelho-intensos }\end{array}$ & & & $X$ & & $X$ & $X$ & $X$ & & $X$ & $X$ & $X$ & & $X$ & $X$ \\
\hline $\begin{array}{c}\text { Ensaios onde houve } \\
\text { dificuldade para realizar o } \\
\text { corte }\end{array}$ & & & & & & $X$ & $X$ & $X$ & $X$ & $X$ & $X$ & & & \\
\hline $\begin{array}{l}\text { Ensaios em que as } \\
\text { sementes mantinham o } \\
\text { tegumento ainda duro } \\
\text { após o preparo }\end{array}$ & $X$ & $X$ & & & & & $X$ & $X$ & & & & & & \\
\hline $\begin{array}{l}\text { Tempo de preparo (corte e } \\
\text { remoção do tegumento - } \\
\text { em minutos) }\end{array}$ & 100 & 100 & 100 & 100 & 90 & 75 & 115 & 85 & 75 & 60 & $\begin{array}{c}10 \\
0\end{array}$ & 60 & 60 & 60 \\
\hline $\begin{array}{l}\text { Ensaios onde houve } \\
\text { facilidade para retirar o }\end{array}$ & & & & & $X$ & & & & $X$ & $X$ & $X$ & & $X$ & $X$ \\
\hline
\end{tabular}

De modo geral, no primeiro ensaio, foi observada a ocorrência de muitos danos provocados pelo corte na extremidade oposta ao embrião bem como do corte longitudinal na lateral da semente. Assim, a dificuldade 
na diferenciação dos danos causados pela realização do corte e danos inerentes à semente pode levar o analista a erros de interpretação. Também Zucareli et al. (2001) ao testarem o corte longitudinal em sementes de Albizia hasslerii submetidas à embebição por 24 horas a $25^{\circ} \mathrm{C}$, com posterior retirada do tegumento, verificaram que as sementes apresentaram coloração uniforme, entretanto, em função das injúrias causadas no local do corte, as sementes apresentaram coloração vermelho-intensa, característica de tecido em intensa atividade respiratória (processo de deterioração), ou branca, típico de tecido morto.

No segundo ensaio, que consistiu em corte na extremidade oposta ao embrião em sementes secas, verificou-se que a extração do tegumento após a pré-embebição por 16 horas em papel foi mais trabalhosa, pois o tegumento permaneceu duro e, com isso foi preciso descascar grande parte da semente, quase na sua totalidade, para extrair o embrião e a membrana interna, caso contrário, os cotilédones partiam-se.

Nesse mesmo ensaio em que as sementes foram précondicionadas diretamente em água por quatro, seis, oito e 16 horas, o período de quatro horas mostrou-se insuficiente para facilitar a retirada do tegumento por dificultar a sua extração e, consequentemente ocasionou muitas injúrias nos cotilédones (Tabela 1).

Com o aumento do tempo de imersão para seis horas foi possível a remoção da membrana interna juntamente com o tegumento externo e os danos foram menos expressivos quando comparados com o período anterior. Por outro lado, houve maior facilidade na remoção do tegumento externo e da membrana interna após o período de oito horas de imersão, com reduzido número de sementes com danos provocados pelo preparo e menor tempo de execução (Tabela 1). Apesar das técnicas de corte e remoção acima descritas proporcionarem vantagens em relação ao tempo de preparo e menor número de interferência na análise das sementes, verificou-se que o corte na extremidade oposta ao eixo embrionário em sementes secas foi difícil de ser realizado demandando maior tempo ( \pm 35 minutos).

Visando sanar essa dificuldade, foi montado o terceiro ensaio, no qual foi testado o mesmo corte realizado no ensaio anterior após duas horas de imersão direta em água, seguido de nova imersão em água por quatro, seis e oito horas. Observou-se que os períodos de seis e oito horas possibilitaram a retirada da membrana interna juntamente com o tegumento externo. No entanto, após oito horas de imersão, houve maior dificuldade, devido ao maior intumescimento e amolecimento das sementes, sendo necessária a retirada de parte do tegumento (auxílio de unha), caso contrário, os cotilédones rasgavam-se ou partiam-se.

Um fator importante a ser considerado nesse ensaio foi o da facilidade de realizar o corte após a imersão em água por duas horas a $25^{\circ} \mathrm{C}$, em relação aos cortes realizados nas sementes sem prévia embebição.

Após a avaliação dos três ensaios resumidos na Tabela 1 , pode-se afirmar que a forma de preparo com melhor resultado foi o da imersão em água por duas horas seguida de corte na extremidade oposta ao eixo embrionário, com mais seis horas de imersão após o corte (Figura 3), por apresentar maior viabilidade de uso, em função da facilidade de corte e posterior remoção do tegumento.

Dentre os fatores a serem considerados no précondicionamento, o teor de água das sementes após o período de hidratação, é um fator muito importante para o desenvolvimento da coloração no teste de tetrazólio. De acordo com Moore (1977), a hidratação promove o amolecimento dos tecidos da semente, facilitando o preparo e a absorção da solução de tetrazólio, além de ativar o sistema enzimático, o que resulta em coloração mais nítida. A recomendação do referido autor é de que a absorção de água deve ser lenta pra evitar a ocorrência de trincas nas sementes ou a lixiviação de substâncias solúveis, principalmente em sementes deterioradas.

No caso das sementes de algodoeiro, o uso de imersão direta em água por até oito horas não foi prejudicial na interpretação dos resultados, uma vez que o tegumento é bastante espesso e possui uma membrana interna aderente ao embrião, servindo como barreira para absorção de água. Contudo, Barros et al. (2005) observaram em sementes de abobrinha, que a utilização da imersão direta das sementes em água por períodos superiores a 30 minutos não foi adequada. Para Costa (1992), o tempo excessivo de exposição das sementes à água pode acarretar problemas devido à redução na disponibilidade de oxigênio para as sementes, comprometendo a sua qualidade e, conseqüentemente, podendo levar à obtenção de resultados incorretos.

Observa-se na Tabela 2 que o teor de água das sementes após o pré-condicionamento foi em torno de $40 \%$ para sementes embebidas por oito horas em água. Nessas condições foi possível a realização do teste de tetrazólio, com redução para oito horas de pré-condicionamento em relação à metodologia tradicional, de 16 horas de hidratação em papel, a $25^{\circ} \mathrm{C}$. Costa e Marcos Filho (1994) também obtiveram resultados satisfatórios para sementes de soja, a partir de $27 \%$ de teor de água, aplicando a metodologia de Costa (1992), com a hidratação das sementes entre papel, durante 6 horas, a $41^{\circ} \mathrm{C}$. 
TABELA 2. Teor de água (\%) das sementes de algodoeiro antes e depois do pré-condicionamento Imersão em água por $2 \mathrm{~h}$, seguida de corte na extremidade distal, com mais $6 \mathrm{~h}$ de imersão em água e posterior remoção do tegumento para o teste de tetrazólio.

\begin{tabular}{cccc}
\hline \multirow{2}{*}{ Safra } & \multirow{2}{*}{ Inicial } & \multicolumn{2}{c}{ Hidratação } \\
\cline { 3 - 4 } & & Papel & Imersão \\
\hline $2005 / 2006$ & 6,3 & 39 & 44 \\
$2006 / 2007$ & 9,0 & 44 & 47 \\
\hline
\end{tabular}

\section{Concentração e temperatura}

Com relação à coloração das sementes, a redução da concentração não prejudicou sua uniformização (Tabela 3), sendo necessário apenas 30 minutos a mais para que as sementes atingissem a tonalidade adequada em relação à concentração de $0,1 \%$ recomendada por Vieira e Von Pinho (1999).

Nota-se ainda, que houve maior amplitude no tempo de permanência para cada fase de coloração das sementes, o que é desejável para os trabalhos de rotina em laboratório, pois possibilita a execução das avaliações em períodos variáveis no decorrer do expediente, sem prejuízo das análises.

Pelos resultados apresentados na Tabela 3, há possibilidade do uso de diferentes concentrações na condução do teste, como já indicado na literatura para outras espécies. Essa variação depende da espécie avaliada, do método de preparo das sementes e da permeabilidade do tegumento (Marcos Filho et al., 1987).

Vale ressaltar que as menores concentrações são mais indicadas por apresentarem menor gasto de sal e por possibilitarem melhor visualização dos distúrbios de coloração e identificação de diferentes tipos de injúrias, sendo que as concentrações mais utilizadas são 0,$075 ; 0,1$; 0,2; 0,5 e 1,0\%. (Marcos Filho et al., 1987; Krzyzanowski et al., 1991; França Neto et al., 1998). Da mesma forma que a concentração, a temperatura de incubação também exerce importante influência sobre a coloração das sementes submetidas ao teste de tetrazólio. Nota-se pela Tabela 3, que a diferença na velocidade para que as sementes atingissem coloração adequada foi de 30 minutos, na medida em que se aumentava a temperatura, tanto para concentração de 0,1 quanto para $0,075 \%$ do sal. Estes resultados vão de encontro às observações realizadas por Vieira e Von Pinho (1999) de que, a cada aumento de $5^{\circ} \mathrm{C}$ na temperatura, ocorre a duplicação na velocidade de reação.

TABELA 3. Avaliação da coloração das sementes de algodoeiro em função da idade (safra), temperatura (T), concentração da solução (C) e do período de exposição em solução de tetrazólio.

\begin{tabular}{|c|c|c|c|c|c|c|c|c|c|c|c|c|c|c|}
\hline \multirow{3}{*}{ Safra } & \multirow{3}{*}{$\mathrm{T}\left({ }^{\circ} \mathrm{C}\right)$} & \multicolumn{13}{|c|}{ Demonstrativo das reações ao sal de tetrazólio } \\
\hline & & \multirow{2}{*}{$\mathrm{C}(\%)$} & \multicolumn{12}{|c|}{ Período de avaliação (minutos) } \\
\hline & & & 30 & 60 & 90 & 120 & 150 & 180 & 210 & 240 & 270 & 300 & 330 & 360 \\
\hline \multirow{6}{*}{$05 / 06$} & \multirow{2}{*}{30} & 0,1 & $\mathrm{CI}$ & $\mathrm{CF}$ & $\mathrm{CF}$ & $\mathrm{CF}$ & $\mathrm{CF}$ & CA & $\mathrm{CA}$ & $\mathrm{CA}$ & $\mathrm{CA}$ & $\mathrm{CA}$ & $\mathrm{CA}$ & $\mathrm{CE}$ \\
\hline & & 0,075 & $\mathrm{CI}$ & $\mathrm{CI}$ & $\mathrm{CI}$ & $\mathrm{CF}$ & $\mathrm{CF}$ & $\mathrm{CF}$ & $\mathrm{CA}$ & $\mathrm{CA}$ & $\mathrm{CA}$ & $\mathrm{CA}$ & $\mathrm{CA}$ & $\mathrm{CA}$ \\
\hline & \multirow{2}{*}{35} & 0,1 & CI & $\mathrm{CF}$ & $\mathrm{CF}$ & $\mathrm{CF}$ & $\mathrm{CA}$ & $\mathrm{CA}$ & $\mathrm{CA}$ & $\mathrm{CA}$ & $\mathrm{CA}$ & $\mathrm{CA}$ & $\mathrm{CA}$ & $\mathrm{CE}$ \\
\hline & & 0,075 & $\mathrm{CI}$ & $\mathrm{CI}$ & $\mathrm{CF}$ & $\mathrm{CF}$ & $\mathrm{CF}$ & CA & $\mathrm{CA}$ & CA & $\mathrm{CA}$ & $\mathrm{CA}$ & CA & CA \\
\hline & \multirow{2}{*}{40} & 0,1 & CI & $\mathrm{CF}$ & $\mathrm{CF}$ & $\mathrm{CA}$ & $\mathrm{CA}$ & CA & $\mathrm{CA}$ & $\mathrm{CE}$ & $\mathrm{CE}$ & $\mathrm{CE}$ & $\mathrm{CE}$ & $\mathrm{CE}$ \\
\hline & & 0,075 & $\mathrm{CI}$ & CI & $\mathrm{CF}$ & $\mathrm{CF}$ & $\mathrm{CA}$ & CA & $\mathrm{CA}$ & CA & $\mathrm{CA}$ & $\mathrm{CE}$ & $\mathrm{CE}$ & $\mathrm{CE}$ \\
\hline \multirow{6}{*}{ 06/07 } & \multirow{2}{*}{30} & 0,1 & $\mathrm{CI}$ & $\mathrm{CF}$ & $\mathrm{CF}$ & $\mathrm{CF}$ & $\mathrm{CA}$ & CA & $\mathrm{CA}$ & $\mathrm{CA}$ & $\mathrm{CA}$ & $\mathrm{CA}$ & $\mathrm{CE}$ & $\mathrm{CE}$ \\
\hline & & 0,075 & CI & CI & CI & $\mathrm{CF}$ & $\mathrm{CF}$ & $\mathrm{CA}$ & $\mathrm{CA}$ & $\mathrm{CA}$ & $\mathrm{CA}$ & $\mathrm{CA}$ & $\mathrm{CA}$ & $\mathrm{CA}$ \\
\hline & \multirow{2}{*}{35} & 0,1 & $\mathrm{CF}$ & $\mathrm{CF}$ & $\mathrm{CF}$ & $\mathrm{CA}$ & $\mathrm{CA}$ & CA & $\mathrm{CE}$ & $\mathrm{CE}$ & $\mathrm{CE}$ & $\mathrm{CE}$ & $\mathrm{CE}$ & $\mathrm{CE}$ \\
\hline & & 0,075 & CI & $\mathrm{CF}$ & $\mathrm{CF}$ & $\mathrm{CF}$ & $\mathrm{CA}$ & CA & CA & CA & CA & CA & $\mathrm{CE}$ & $\mathrm{CE}$ \\
\hline & \multirow{2}{*}{40} & 0,1 & $\mathrm{CF}$ & $\mathrm{CF}$ & CA & $\mathrm{CA}$ & $\mathrm{CE}$ & $\mathrm{CE}$ & $\mathrm{CE}$ & $\mathrm{CE}$ & $\mathrm{CE}$ & $\mathrm{CE}$ & $\mathrm{CE}$ & $\mathrm{CE}$ \\
\hline & & 0,075 & CI & $\mathrm{CF}$ & $\mathrm{CF}$ & $\mathrm{CA}$ & $\mathrm{CA}$ & CA & $\mathrm{CA}$ & CA & $\mathrm{CE}$ & $\mathrm{CE}$ & $\mathrm{CE}$ & $\mathrm{CE}$ \\
\hline
\end{tabular}

CI - início da coloração; CF - coloração fraca; CA - coloração adequada; CE - coloração excessiva. 
Como o período de tempo necessário para o desenvolvimento de coloração das sementes pode variar em relação à idade das sementes, verificou-se a partir de amostras provenientes das safras 2005/2006 e 2006/2007 (Tabela 3), que as sementes mais jovens apresentaram maior velocidade para obtenção da coloração adequada, por serem mais vigorosas, com $95 \%$ de germinação, iniciam suas atividades mais rapidamente que as sementes mais velhas, com $80 \%$ de germinação, apesar de serem mais permeáveis, apresentaram menor eficiência na coloração.

Desta forma, a redução da concentração para $0,075 \%$ não foi prejudicial mesmo para as sementes mais vigorosas, diferentemente do que afirmaram Delouche et al. (1976), que os tecidos vigorosos, geralmente túrgidos, poderiam apresentar maior barreira à penetração do sal de tetrazólio, colorindo de forma lenta e uniforme, ao contrário das sementes velhas e deterioradas, que geralmente colorem mais rapidamente e desenvolvem coloração vermelho-carmim.

\section{Validação da metodologia alternativa}

Pelos resultados apresentados na Tabela 4, verifica-se que houve concordância entre a classificação obtida pelo teste de tetrazólio, utilizando a metodologia proposta no presente estudo, com o teste de germinação.

TABELA 4. Valores médios (\%) da primeira contagem (PCG), do teste de germinação (TG) e de sementes viáveis, vigorosas e inviáveis pelo teste de tetrazólio (TZ) em sementes de algodoeiro.

\begin{tabular}{cccccc}
\hline \multirow{2}{*}{ Lote } & \multirow{2}{*}{ PCG } & \multirow{2}{*}{ TG } & \multicolumn{3}{c}{ TZ (classes) } \\
\cline { 4 - 6 } & & & Vaiáveis & Vigorosas & Inviáveis \\
\hline 1 & $71 \mathrm{~b}$ & $85 \mathrm{~b}$ & $89 \mathrm{ab}$ & $85 \mathrm{~b}$ & $11 \mathrm{~b}$ \\
2 & $55 \mathrm{c}$ & $80 \mathrm{~b}$ & $84 \mathrm{~b}$ & $76 \mathrm{c}$ & $16 \mathrm{~b}$ \\
3 & $46 \mathrm{~d}$ & $79 \mathrm{~b}$ & $84 \mathrm{~b}$ & $66 \mathrm{~d}$ & $16 \mathrm{~b}$ \\
4 & $30 \mathrm{e}$ & $65 \mathrm{c}$ & $69 \mathrm{c}$ & $63 \mathrm{~d}$ & $31 \mathrm{a}$ \\
5 & $92 \mathrm{a}$ & $94 \mathrm{a}$ & $95 \mathrm{a}$ & $95 \mathrm{a}$ & $4 \mathrm{c}$ \\
\hline
\end{tabular}

Desta forma, pode-se inferir que a indicação da metodologia alternativa proposta neste estudo, de preparo e pré-condicionamento das sementes, que foram cortadas na extremidade oposta ao eixo embrionário após duas horas de imersão em água seguida de mais seis horas de imersão depois do corte, utilizando-se para coloração a concentração a $0,075 \%$ a $40^{\circ} \mathrm{C}$, foi possível facilitar a remoção do tegumento, reduzir o tempo de preparo e a concentração da solução sem prejuízo na interpretação dos resultados.

Vale ressaltar que os resultados obtidos nas diversas etapas de condução do teste de tetrazólio foram determinantes para redução do tempo total de avaliação da viabilidade e vigor de sementes de algodoeiro. Os resultados do teste que antes eram obtidos em 24 horas, após este estudo, poderão ser informados em até 12 horas.

Diante dos resultados obtidos e considerando-se que o fator tempo, aliado ao menor gasto do sal, são características desejáveis na realização do teste de viabilidade de sementes para obtenção de resultados de análises em laboratório, recomenda-se, para sementes dessa espécie, a combinação de temperatura/concentração do sal de tetrazólio de $40^{\circ} \mathrm{C} / 0,075 \%$ por duas horas e meia de exposição.

\section{CONCLUSÕES}

O tempo de preparo das sementes de algodoeiro para a condução do teste de tetrazólio pode ser reduzido quando as sementes são cortadas na extremidade oposta ao eixo embrionário após duas horas de imersão em água, seguida de mais seis horas de imersão depois do corte.

A concentração de $0,075 \%$ da solução do sal de tetrazólio, a temperatura de $40^{\circ} \mathrm{C}$ e o tempo de 150 minutos de exposição são adequados para a coloração uniforme das sementes de algodoeiro.

\section{REFERÊNCIAS}

ARAÚJO, R.F.; ALVARENGA, E.M.; LIMA, W.A.A.; DIAS, D.C.F.S.; ARAÚJO, E.F. O uso do teste de tetrazólio para avaliar a viabilidade de sementes de café (Coffea arabica L.). Informativo ABRATES, v.7, n.1/2, p.109, 1997.

BARROS, D.I.; BHERING, M.C.; DIAS, D.C.F.S.; DIAS, L.A.S.; ARAÚJO, E.F. Uso do teste de tetrazólio para avaliação da qualidade fisiológica de sementes de abobrinha. Revista Brasileira de Sementes, v.27, n.2, p. 165-171, 2005.

BHERING, M.C.; SILVA, R.F.; ALVARENGA, E.M.; DIAS, D.N.F.S.; PENA, M.F. Avaliação da viabilidade e do vigor das sementes de feijão-de-vagem (Phaseolus vulgaris L.) pelo teste de tetrazólio. Viçosa: UFV, 1996. $27 \mathrm{p}$.

BHERING, M.C.; SILVA, R.F.; ALVARENGA, E.M.; DIAS, D.C.F.S.; PENA, M.F. Metodologia do teste de tetrazólio em sementes de feijão. In: KRZYZANOWSKI, 
F.C.; VIEIRA, R.D.; FRANÇA NETO, J.B. (Ed.). Vigor de sementes: conceitos e testes. Londrina: ABRATES, 1999. p.8.3-1 - 8.3-10.

BITTENCOURT, S.R.M.; VIEIRA, R.D. Metodologia do teste de tetrazólio em sementes de amendoim. In: KRZYZANOWSKI, F.C.; VIEIRA, R.D.; FRANÇA NETO, J.B. Vigor de sementes: conceitos e testes. Londrina: ABRATES, 1999. cap. 8.2, p.1-8.

BRASIL. Ministério da Agricultura e da Reforma Agrária. Regras para análise de sementes. Brasília, DF: SNDA/ DNDV/CLAV, 1992, p.157.

COSTA, N.P. Metodologia alternativa para o teste de tetrazólio em sementes de soja. Piracicaba, 1992. 132f. Tese (Doutorado em Fitotecnia) - Escola Superior de Agricultura "Luiz de Queiroz", Universidade de São Paulo.

COSTA, N.P.; MARCOS FILHO, J. O emprego do teste de tetrazólio na avaliação da qualidade da semente de soja. Informativo ABRATES, Londrina, v.4, n.2, p.53-62, 1994.

DELOUCHE, J.C.; STILL, T.W.; RASPET, M.; LIENHARD, M. O teste de tetrazólio para viabilidade de sementes. Brasília, DF: AGIPLAN, 1976. 103p.

DIAS, M.C.L.L.; ALVES, S.J. Avaliação da viabilidade de sementes de Panicum maximum jacq pelo teste de tetrazólio. Informativo ABRATES, Londrina, v.11, n.2, p. 317, 2001.

DIAS, M.C.L.L.; BARROS, A.S.R. Metodologia do teste de tetrazólio em sementes de milho. In: KRZYZANOWSKI, F.C.; VIEIRA, R.D.; FRANÇA NETO, J.B. Vigor de sementes: conceitos e testes. ABRATES. 1999. p.8.4-1 8.4-10.

FRANÇA NETO, J.B.; KRZYZANOWSKI, F.C.; COSTA, N.P. O teste de tetrazólio em sementes de soja. Londrina: EMBRAPA- CNPSo, 1998, 72p.
FRANÇA NETO, J.B. Testes de tetrazólio para determinação do vigor de sementes. In: KRZYZANOWSKI, F.C.; VIEIRA, R.D.; FRANÇA NETO, J.B. Vigor de sementes: conceitos e testes. Londrina: ABRATES, 1999. cap.8, p.1-7.

GRABE, D.F. Manual do teste de tetrazólio em sementes. Brasília, DF: AGIPLAN, 1976. 85p.

KRZYZANOWSKI, F.C.; FRANÇA NETO, J.B.; HENNING, A.A. Relato dos testes de vigor disponíveis para as grandes culturas. Informativo ABRATES, v.1, n.2, p.1550, 1991.

MARCOS FILHO, J.; CICERO, S.M.; SILVA, W.R. Avaliação da qualidade das sementes. Piracicaba: FEALQ, 1987. 230p.

MENDONÇA, E.A.F.; RAMOS, N.P.; PAULA, R.C. Viabilidade de sementes de Cordia trichotoma (Vellozo) Arrabida ex Steudel (louro-pardo) pelo teste de tetrazólio. Revista Brasileira de Sementes, v.23, n.2, p.64-71, 2001.

MENDONÇA, E.A.F; COELHO, M.F.B; LUCHESE, M. Teste de tetrazólio em sementes de magava-brava (Lafoensia pacari St.Hil. - Lythraceae). Revista Brasileira de Plantas Medicinais, v.8, n.2, p.33-38, 2006.

MOORE, R.P. Tetrazolium testing handbook. Raleigh: North Carolina State University, 1977. Paginação irregular.

VIEIRA, M.G.G.C.; VON PINHO, E.V.R.V. Metodologia do teste de tetrazólio em sementes de algodão. In: KRZYZANOWSKI, F.C.; VIEIRA, R.D., FRANÇA NETO, J.B. Vigor de sementes: conceitos e testes. Londrina: ABRATES, 1999. p.8.1-1 - 8.1-13.

ZUCARELI, C.; MALAVASI, M.M.; FOGAÇA, C.A.; MALAVASI, U.C. Preparo e coloração de sementes de farinha-seca (Albizia hasslerii (Chodat) Burr.) para o teste de tetrazólio. Revista Brasileira de Sementes, v.23, n.2, p.186-19, 2001. 